\title{
Values in Family Therapy Practice and Research: An Invitation for Reflection
}

\author{
Stephen T. Fife
}

Jason B. Whiting PhD

Brigham Young University, jason.whiting@byu.edu

Follow this and additional works at: https://scholarsarchive.byu.edu/facpub

Part of the Marriage and Family Therapy and Counseling Commons

\section{Original Publication Citation}

Fife, S. T., \& Whiting, J. B. (2007). Values in family therapy research and practice: An invitation for reflection. Contemporary Family Therapy, 29, 71-86, DOI: 10.1007/s10591-007-9027-1

\section{BYU ScholarsArchive Citation}

Fife, Stephen T. and Whiting, Jason B. PhD, "Values in Family Therapy Practice and Research: An Invitation for Reflection" (2007). Faculty Publications. 2166.

https://scholarsarchive.byu.edu/facpub/2166

This Peer-Reviewed Article is brought to you for free and open access by BYU ScholarsArchive. It has been accepted for inclusion in Faculty Publications by an authorized administrator of BYU ScholarsArchive. For more information, please contact ellen_amatangelo@byu.edu. 


\title{
Values in Family Therapy Practice and Research: An Invitation for Reflection
}

\author{
Stephen T. Fife $\cdot$ Jason B. Whiting
}

Published online: 4 May 2007

(C) Springer Science+Business Media, LLC 2007

\begin{abstract}
Values have been shown to be a pervasive part of both marriage and family therapy (MFT) clinical practice and research. Yet, many therapists and researchers remain unclear about how values affect their work. This article examines the influence of Western philosophical assumptions and therapy traditions in light of current understandings of values in therapy. The influence of values in MFT research processes is similarly examined. Implications for how family therapy professionals can be more reflective and sophisticated in their understanding of values in clinical practice and scientific inquiry are discussed. Suggestions for addressing values in MFT training also are given.
\end{abstract}

Keywords Values · Marriage and family Therapy $\cdot$ Research $\cdot$ Supervision

\section{Introduction}

Family therapists today generally acknowledge that value-free therapy is not possible (Doherty \& Boss, 1991; Gladding, Remley, \& Huber, 2001), and many authors have critiqued the ideal of "objective" research and clinical work (e.g., Melito, 2003; Slife, 2004). Fowers (2001) observed that "research and therapy are not guided by disinterested theory that provides neutral accounts of how things operate. Rather we are inescapably involved in expressing, challenging, strengthening, and shaping contemporary perspectives on what is of value"' (p. 337). Therapy is an interactive process that deals with relationships, growth, and happiness. It addresses questions of right or wrong living, good and poor relationships, as well

\footnotetext{
S. T. Fife $(\bowtie)$

Department of Marriage and Family Therapy, University of Nevada, 4505 Maryland Parkway, Box 453045, Las Vegas, NV 89154-3045, USA

e-mail: stephen.fife@unlv.edu

J. B. Whiting

Marriage and Family Therapy Program, University of Kentucky, Lexington, KY, USA
} 
as choice and accountability. Values also pervade marriage and family therapy (MFT) research processes, including research questions, methods, and results. Both therapy and research are human endeavors in which the influence of participants' values is inescapable.

Although many marriage and family therapists agree that values are inseparable from family therapy research and clinical process, the implications of this conclusion are less clear. Fowers (2001) noted, "There are precious few examples of how we can constructively address the ambiguities of ethical and moral matters in our professional work that go beyond admitting the presence of personal biases" (p. 328). The topic of values continues to be discussed and debated in the field (e.g., Melito, 2003), and it is important for MFT scholars and clinicians to consider what significance values have in their work. Becoming more reflective and conscientious about values will help professionals to be more effective family therapists, researchers, and educators (Aponte, 1985; Odell \& Stewart, 1993).

The purpose of this article is to examine how values are a part of MFT practice and scholarship and to suggest constructive ways of improving our professional work by understanding the role of values within it. We do this first, by reviewing the historical basis for values avoidance in MFT; second, by identifying the manifestation of values in MFT practice and research; and third, by providing guidelines on how investigators and therapists can be more reflective about values in their work.

\section{Defining Values}

According to Rokeach (1973), a value is "an enduring belief that a specific mode of conduct or end-state of existence is personally or socially preferable to an opposite or converse mode of conduct or end-state of existence" (p. 5). Jensen and Bergin (1988) describe values in therapy as "orienting beliefs about what is good or bad for clients and how that can best be achieved" (p. 290). Values include judgments between degrees of worth, or of esteeming one course of action, outcome, or ideal above another. In this sense, values are more than preferences, they include a dimension of obligation or requirement-an implied shouldness of conduct (Patterson, 2000). Values are the standards by which evaluations are made, and they inform the attitudes, decisions, and behaviors of individuals and groups (Rokeach, 1973).

Historically, therapists have tended to avoid values discussions in clinical conversations (Jensen \& Bergin, 1988; Thomas, 1994). Values have sometimes been avoided because of their religious or moral connotation (Richards \& Bergin, 1997). A fear of imposing values on clients also has led some therapists to sidestep values issues (Tjeltveit, 1986). Others have attempted to avoid values because of clinical training or because they are unsure of how to address values with clients. Likewise, researchers have tried to avert the influence of values in their work, fearing a contamination of data and results.

Despite an historical reluctance to acknowledge values, it is theoretically and pragmatically impossible for therapists and researchers to maintain a value-neutral position. Not only do clinicians and scientists operate from value-laden positions, but theories of human behavior and research methodology also contain values imbedded in their explanations of human beings and relationships.

\section{Values and Ethics}

Although the words "values" and "ethics" are often used synonymously, they have distinct meanings. Professional ethics are standards for appropriate conduct, which are 
often formalized by professional organizations (Brock, 1993; Corey, Corey, \& Callanan, 2003). For example, marriage and family therapists have the AAMFT Code of Ethics; and MFT books and conference presentations have addressed the topic of professional ethics (e.g., Gladding et al., 2001; Del Campo, Roney, Pais, \& Campbell, 2003). As described by Doherty and Boss (1991), ethics relate to decisions about therapist behaviors and whether certain courses of action are appropriate according to the profession's standards. In this sense, ethics address the do's and don'ts of professional conduct, such as when to break or maintain confidentiality, how to maintain appropriate relationships with clients, or how to give informed consent. Values, on the other hand, are core beliefs of what is good and desirable. Therefore, therapists' values will always influence their actions, but this derives from an internal source (a moral sense of what is the best action to take) rather than an external one (following a professional code). Although ethical codes derive from professional and social values, they address only a small number of the choices made in the professional activities of marriage and family therapists.

\section{An Invitation for Reflection}

In 1991 Doherty and Boss asserted, “As of the early 1990's, the myth of value neutrality is dead-at least as an issue of professional debate" (p. 611). However, we question whether the issue is dead in the actual practice of family therapy research, training, and clinical work. For example, much attention is given to the way research and therapy should be carried out (which shows evidence of values). However, an examination of how values come into play is often overlooked by researchers and clinicians. Some retain an ideal of objectivity and assume that therapy and research can be conducted in a value-neutral manner. Others argue that since value-neutrality is impossible, we should ignore scientific research and theory altogether. Some equate values with moralizing and rigidity; whereas others worry that accepting value-neutrality encourages an "anything goes" mentality, or unaccountable relativism (Doherty, 1995; Melito, 2003).

Generally, such polarized positions are unproductive, and it is likely that few MFT professionals explicitly espouse views on the ends of this spectrum. However, we assert that (a) the ideal of value-neutrality maintains an influence in the training, research, and clinical work of many family therapists, and (b) values often remain hidden beneath the technical aspects and language of MFT practice and research. This article contributes to the values discussion by inviting readers to reflect on the role of values in their clinical and research activities.

\section{Values in MFT Practice and Research}

\section{Values in MFT Clinical Process}

Psychotherapy has historically tried to distance itself from values. Early therapy pioneers were instrumental in shaping this view, asserting that therapy was to be a technical, valuefree procedure. "Like surgery, [psychotherapy] was intended to be an objective approach that did not involve the values of the practitioner in a direct way. Since the time of Freud, it has been a goal of most therapists to suppress their own beliefs and avoid shaping the values of clients"' (Jensen \& Bergin, 1988, p. 290). By adopting this ideal, clinicians were thought to avoid the contaminating influence of values, as well as the imposition of values on their clients. 
The ideal of objectivity and value-neutrality has influenced nearly all major theories in the therapy disciplines. Fisher-Smith (1999) illustrated how this ideal has been promoted in the three main forces of psychotherapy: psychoanalytic, behavioristic, and humanistic theories. These theories inform many of the therapy models taught in MFT graduate programs, and the notion of value-free therapy has been incorporated into many family systems approaches to therapy (Carlson \& Erickson, 1999; Thomas, 1994). Hare-Mustin (1987) argues that the assumption of objectivity is "so embedded in the therapeutic system and, in fact, in Western thinking as to rarely receive comment" (p. 16). One family therapist echoes this common attitude: "In my work,...I generally believe that my particular values...are irrelevant to the job of doing therapy", (Micucci, 1998, p. 197).

Although the therapeutic ideal of neutrality persists in many clinical philosophies and practices, this has been challenged for many years. For example, as early as 1958, Watson wrote that "one of the falsehoods with which some therapists console themselves is that their form of treatment is purely technical, so they need take no stand on moral issues"' (p. 575). Bergin (1980) also argued, "As an applied field, psychotherapy is directed toward practical goals that are selected in value terms.... This necessarily requires a philosophy of human nature that guides the selection of measurements and the setting of priorities regarding change'" (p. 97).

\section{Values of MFT Theories and Models}

Although they often remain unrecognized, values are inherent in all MFT theories and models (Aponte, 1985), and values influence what therapists focus on in assessment, conceptualization, intervention, and evaluation. For example, psychodynamic family therapy approaches emphasize unconscious processes, early childhood experiences, and insight. Behavioral family therapy approaches stress observable behavior, reinforcement as a means of bringing about change, and the therapist as expert or director. On the other hand, postmodern therapies embrace clients' expertise, multiple perspectives, and the cocreation of meaning. Emotionally-focused therapy focuses on interpersonal attachments and client emotions, and Bowenian family therapy attends to intergenerational transmission of family patterns and differentiation. Each theory places emphasis on certain aspects of individuals and families, while deemphasizing others.

One of the reasons that family therapists may not critically examine theory-based values is because many early MFT models emerged from a mechanistic tradition that was assumed to be value-free. Although family therapy rejected much associated with linear, individual psychotherapy models, many systemic concepts retain mechanistic assumptions and the notion of neutrality (Slife, 1993). Interestingly, general system theory pioneer Von Bertalanffy promoted an organic, "living" systems metaphor that he felt was more appropriate to human behavior than a mechanistic, "clock-like" system (Nichols \& Schwartz, 2006). He criticized the cybernetic versions of systems theory that were proliferating because of their presumed neutrality and lack of humanity. He also believed that therapists should scrutinize their personal values and those implicit in their theories. Although more recent postmodern theorists have recognized the impossibility of being neutral, the values inherent in MFT models and theories often remain hidden.

Because of the bias and limitations of all theories and therapy models, some have suggested that therapists should practice without using theory. Some clinicians adopting this position claim that therapy is a technical endeavor, believing that interventions and techniques can be applied atheoretically. However, this attempt to avoid theory is itself a theory, 
with implicit values (Slife \& Williams, 1995). Others have tried to escape theory by favoring spontaneity, the primacy of human experience, and avoiding technique. This also illustrates the inevitability of values, as certain ideas and behaviors are valued above others.

Rather than throw out the theoretical baby with the bathwater by dismissing theory, it is important for professionals to recognize the role of theory in practice. This includes recognizing that theory is a lens for sorting our perceptions, and will influence what we value in our clients and in our work with them. It is easy to forget the influence of theoretical ideas. As Albert Einstein observed: "Concepts which have proved useful for ordering things easily assume so great an authority over us that we forget their terrestrial origin and accept them as unalterable facts... Scientific progress is frequently blocked for long periods by such errors'" (as cited in Holton, 1988, p. vi).

Given psychotherapy's obsession with models and techniques (Hubble, Duncan, \& Miller, 1999), therapists may place disproportionate emphasis on them in their work with families. When therapists conceptualize clients and cases in model-specific jargon they risk minimizing the personhood of the client, thus forsaking meaning and clinical description (Coles, 1989; Doherty, 1995). It may be that therapists are more comfortable speaking in technical terminology than engaging in moral conversations. Due to limited language and guidance, therapists may feel awkward when talking about values with clients and may resist doing so even when appropriate. For example, a therapist may feel that it would be helpful to shift from communication skills training with a couple to pursue a value-rich discussion of the wife's struggle with her obligation to her aging father. This therapeutic move, which may include discussion of the client's and the therapist's values, may cause a struggle for the therapist because he or she may feel that this deviates from "best practice" guidelines or formalized theory. Nevertheless, although this type of intuitive deviation from clinical models to engage in moral discussions is not something most therapists are trained to do, many do it because of its therapeutic value (Jensen, Bergin, \& Greaves, 1990; Whiting, Nebeker, \& Fife, 2005).

\section{Values of MFT Clinicians}

In addition to the values inherent in therapeutic models, family therapists regularly make value-based judgments in their clinical work. "The idea of therapeutic neutrality denies the fact that all therapists hold normative concepts of good and poor functioning, growth and stagnation, male and female"' (Hare-Mustin, 1987, p. 16; see also Aponte, 1985). Therapists have values that cannot be suspended, left at home, or checked at the door of the therapy room. Without values, a therapist would be paralyzed, being void of any impetus for action. To illustrate this, try to imagine a therapist who has no values. This person would not value one behavior or outcome above another. Nor would the therapist be able to have a meaningful relationship or engagement with a client, as the client would not be valued for his or her life and experiences. Even if this kind of value-neutrality were possible, would one want to refer a family member to this empty, machine-like entity?

To assume value-neutrality in our work with individuals, couples, and families is to deny an essential part of the common ground that we share with our clients and may distance us from their lives and experiences. Goldner (1988) has suggested that the marginalization of values "has led to [a] kind of bad therapy, a therapy that silences discussion of the moral dimensions of...life" (p. 29). She continues, "To sidestep questions of right and wrong because of a crude misunderstanding of what constitutes the proper domain of psychotherapy is to be inauthentic and psychologically distant from people's experience', (p. 29). 
One common attempt to avoid the influence of personal values and biases is to refer (or defer) to scientific research. For example, a therapist may preface a suggestion or intervention with, "The research says that..." or "Studies show..." However, practitioners who choose to rely on scientific findings in an effort to avoid values fail to recognize that they may be invoking values on at least three levels. First, they may be advocating the values inherent in scientific research. Second, they are giving precedence to the kind of knowledge produced by scientific research. Holding science as the best source of knowledge and the best guide to human behavior is a value judgment. Third, therapists who incorporate research findings must make judgments as to what research findings will be most relevant, meaningful, and helpful to the clients. Therapists will likely gravitate toward research that supports their own values and may prescribe a course of action accordingly. As Mowery and Walters (2005) have argued, "The jump from empirical data... to a recommended course of action at the practical level, always involves the presence of value judgments... In other words: (A) empirical facts + (B) values statements $=(\mathrm{C})$ prescriptive conclusions" (pp. 608-609, italics in original).

The values of family therapists will also influence their choice of therapy models. Marriage and family therapists have been criticized for uncritically following therapy "'gurus"' (Crane, Wampler, Sprenkle, Sandberg, \& Hovestadt, 2002). However, one reason this may happen is that what these experts do with families resonates with the personhood of other therapists, including their values about relationships and therapy. Although it is possible that the research base behind a particular model of therapy is what persuades therapists to subscribe to a model, it is also likely that they choose approaches that fit with their personal experience and beliefs about how people change and how therapists should relate with people.

The experiential knowledge that comes from clinical practice is one way of knowing what works in therapy, as is empirical research, and "both [are] to be valued, and both [are] to be questioned"' (Sprenkle \& Piercy, 2005, p. 4). When family therapy models are critiqued only through an evidence-based lens that values certain kinds of evidence and knowledge, other legitimate forms of knowing may be left unheard (Addison, Sandberg, Corby, Robila, \& Platt, 2002). Although empirical evaluation of approaches is one tool to help us examine our clinical models, it is a limited one. Not surprisingly, when using empirical methods to evaluate therapy effectiveness, the models whose values most closely align philosophically with empiricism have been found to be most effective (Slife, 2004).

\section{Values in MFT Research}

Value-neutrality has been perpetuated as a therapeutic ideal, in part, by the influence of research traditions. In an effort to become more recognized and respectable, the behavioral sciences sought to distance themselves from philosophy and subjective opinion by adopting a formal method to guide their research - the scientific method. This method was developed by scholars in the natural sciences (i.e., physics, chemistry, etc.) as a means of studying the natural world (Polkinghorne, 1983). Based on the respectability and success of the scientific method in the natural sciences, the behavioral sciences adopted the scientific method as the principal strategy for studying human behavior and human interaction. In doing so, the behavioral and therapeutic disciplines embraced the theoretical assumptions and values inherent in scientific inquiry.

Inherent in the scientific method is the ideal of objectivity (Blow \& Hartnett, 2005). As one of its hallmarks, "natural science seeks to discover the nature of objects 
without reference to the subject'" (Brennan, 1995, p. 125), or without interference by the subjective perceptions or values of the observer. The scientific method has traditionally been seen as a neutral, transparent window to the world "out there" (i.e., the "real" world that is assumed to exist separate from our subjective experience) (Slife, Hope, \& Nebeker, 1999). Social scientists were in part attracted to the scientific method because it required controlled and, therefore, seemingly objective conditions. Such conditions are thought to mitigate researcher bias, thus producing unconfounded data and results. Knowledge revealed through the scientific method is thus taken to be objective, or free from bias (Slife \& Williams, 1995). Such knowledge is believed to be more pure, more true to reality, and thus more valuable than knowledge produced by other means. As Wampler (2002) notes: "Many have accepted the premise that research is a 'good' and that, almost without question, the conclusions drawn from research must also be good', (p. 1).

The assumptions that scientific knowledge is objective and inherently good have been challenged. Scholars in the philosophy of science have argued that despite its historical reputation, the scientific method is not a neutral, objective method of inquiry. Instead of being neutral, the scientific method carries with it many underlying assumptions and values that have significant implications for the research questions asked, the kind of information that is gathered, and the meaning given to research results (Packer \& Addison, 1989; Slife et al., 1999). The Newtonian paradigm that is fundamental to the scientific method includes the positivistic assumptions of linear time, causality, universal laws of nature, determinism, empiricism, objectivity, atomism, reductionism, replicability, and the subject/object distinction (see Polkinghorne, 1983; Slife, 1993; Slife \& Williams, 1995 for further discussion). Feminist (Goldner, 1988) and postmodern scholars (Packer \& Addison, 1989; Slife \& Williams, 1995) have shown that there are many cultural and scholarly biases within the assumptions of the scientific research paradigm. They question the possibility of conducting research in a value-free manner.

Packer and Addison (1989) elaborate:

The empiricist researcher aims to achieve what might be called an absolute perspective; a God's eye view, from which the world could be described in objective terms. Such a perspective would be distinct from that of any particular observer. The researcher must try to become detached from any personal involvement and adopt what Nagel (1986) calls 'the view from nowhere.' But cultivating the appropriate 'scientific attitude' is hardly a matter of mere procedure. Being value-neutral, free from prejudice, objective and unbiased (to the small extent that these are possible at all) involves adopting a special posture of distance from or denial of one's personal interests and concerns. And being unconcerned or disinterested is as little achieved through procedures and techniques as is being concerned. Paradoxical though it sounds, detachment is itself a kind of perspective, a way of viewing the world that cannot be reduced to technique. (p. 27)

Method cannot free the researcher or the research process from the influence of values. Scientific research is fundamentally a human endeavor, and the ways in which researchers conceptualize problems, formulate questions, design studies, make observations, and interpret results are all informed by the values and assumptions that the researchers hold. 


\title{
Implications for MFT Practioners, Supervisors, and Researchers
}

\author{
Implications for MFT Practice and Supervision
}

Although it is clear that values are an unavoidable part of family therapy, helpful ways in which therapists might deal with values in therapy have not been widely discussed or adopted. Fisher-Smith (1999) found that therapists used either one of two strategies to deal with values in sessions: a neutrality mode of action or a disclosure mode of action. Those using the neutrality mode attempted to set aside their values and remain neutral in therapy. Those employing the disclosure mode were explicit in sharing their values with clients during therapy.

Similar to the disclosure mode found by Fisher-Smith, (1999), others have suggested that therapists should disclose their values when they are relevant to the therapy conversation (Richards \& Bergin, 1997; Vachon \& Agresti, 1992). This may be particularly important as some studies have shown that clients often are influenced by the values of the therapist (e.g., Beutler, 1979; Patterson, 2000). Jensen and Bergin (1988) recommend that therapists be explicit in sharing their values with clients, respect clients' self-determination, and not force them to adopt the therapists' values. Others have argued that family therapists should work within clients' value systems, and attempts to change their values should be preceded by the clients' request (Lageman, 1993). Both of these approaches value the respecting of clients' values and their right to self-determination (Melito, 2003).

Respect for clients' values does not necessitate an avoidance of values or values discussions in therapy. Rather, a respectful therapeutic approach may, in some cases, require a discussion of values. This is illustrated by an excerpt from a graduate student paper on personal values in therapy (used with permission):

When I first started counseling in a substance abuse treatment facility, I was constantly aware of trying to present a neutral interpretation of clients' options. I thought I would be most helpful and informative if I created a safe and trusting environment, but veered away from my ideas and values to avoid potentially offending clients. Within a few months, one of my more outspoken but friendly clients confronted me about my approach to counseling. Our ensuing conversation sounded something like this:

"What the hell am I paying you for if you don't help me make better decisions? You always just ride the fence."

"Well, we've gone over all your options and the pros and cons of each one. It's up to you to decide what you want to do."

“'Obviously, I wouldn't be here if I was any good at making decisions by myself! I want you to tell me what you think."

"I prefer to remain neutral because I don't want to bias your decision one way or the other with my opinions and beliefs."

"First of all, don't think I'm going to listen to you just because you say what you think. I make my own decisions. Anyway, you're not that smart. Second of all, I wouldn't still be seeing you if I didn't think you wanted to help me. So, if you have stupid ideas when you start talking again, I'm not going to listen to them. But maybe if you have a good one that I haven't considered, I will have gotten my money's worth.', 
Our subsequent discussions about what I believed about his options were peppered with hesitant personal suggestions, but I gained more respect from that client for bringing up my opinions when appropriate than for remaining neutral.

By avoiding values or attempting to present a value-neutral façade, therapists may be missing opportunities to be helpful to their clients. Peterson and Seligman (2004) have argued that the moral dimension of life, which has been historically neglected by psychotherapists, is strongly associated with happiness and life satisfaction. They suggest that moral choices, responsibility, and virtues be addressed and brought to the forefront of clinical work.

Doherty's (1995) work with incorporating moral language into therapy is a notable example of how one might work within the value-laden nature of the clinical process. He suggests that discussions about client and therapist values are important to help clients identify or clarify their values and evaluate their behavior. When clients are engaged in a discussion about values, they are invited to consider the morality of their behavior in light of the values that they hold. This is similar to Michael White's (1993) invitation to reflection that he offers clients when he asks them if they are doing things in their families that go against their own better judgment.

When appropriate, a therapist can bring up moral issues in a way that respects the client's values, even if the therapist's values are different from the client's. Doherty suggests that an evaluation of values should not take place in the therapist's head (i.e., deciding that the client's values are good or bad), but should take place within the therapeutic dialogue, "in conversations in which the therapist listens, reflects, acknowledges, question, probes, and challenges — and in which the client is free to do the same" (1995, p. 37). Discussions about values can occur without the therapist being judgmental or coercive.

Corey et al. (2003) suggest that value differences are inevitable and that there may be occasions when this interferes with the therapeutic relationship and client progress. They note, however, that value conflicts can be worked through effectively, and having differing values does not necessitate a referral-something they see as a last resort. They suggest several questions for therapists to consider in such situations, including:

Why do you think you would have difficulty working with this client? Why is it necessary that there be congruence between your value system and that of the client? What are the ethical ramifications of declining to work with the client? What are the potential risks and benefits of making a referral? What are the possible risks and benefits if you choose to work with the client? (pp. 77-78)

In addition to personal reflection, they recommend that therapists seek consultation/ supervision in cases when value differences pose a challenge. In such situations, it is the therapist's responsibility to deal with this challenge constructively without abandoning the client (Thomas, 1994).

Each of the ideas about handling therapist values presented above presumes that therapists are aware of the influence their values have in therapy. One approach to heighten awareness of values is to encourage therapists to identify the values they hold and how these might influence their work with clients. Therapists also may ' be asked to consider their personal positions on such issues as marriage, divorce, gender roles, child rearing, sexual attitudes and behaviors, birth control, abortion, spirituality, extramarital affairs, suicide, and child abuse (Corey et al., 2003; Gladding et al., 2001). 
In our work with therapists-in-training, we give them a "Personal Beliefs" assignment in which they are asked to articulate their beliefs about the nature of individual and family problems, how change occurs, the purpose of therapy, the role of the therapist, and so on. We also ask them to consider where these beliefs originated, how they came to have them, and what influence their beliefs will have in their work with clients. This helps them become more aware of the assumptions, beliefs, and values that will inform their clinical work.

Carlson and Erickson (1999) suggest several reflection questions to help family therapists recognize the relationship between values and their chosen theoretical orientation:

In what ways have your personal values and/or beliefs influenced your chosen theoretical orientation? In what ways has your chosen theoretical orientation influenced your own personal values and/or beliefs? How do the values of your chosen theoretical orientation fit with your own personal values and/or beliefs? (p. 66)

They suggest that the process of examining how one's values fit with the values of the theories used will result in a more personally consistent approach to therapy. Therapists who become more cognizant of their own values will also be better prepared to engage in meaningful and therapeutic conversations with their clients about values.

\section{Case Study}

The following clinical example illustrates the influence of the value-neutral tradition, the practical struggle that can arise from it, and possible therapist and supervisor responses. Consider the case of Elizabeth, a marriage and family therapist who is finishing her hours for state licensure. She is seeing Mark and Melissa, a young couple having marital problems. Elizabeth is frustrated with Mark's domineering attitude towards his wife, especially as it relates to gender roles. She feels that he uses his family of origin as well as his religious beliefs as excuses to control and be demanding of his wife and their young son.

Elizabeth's early goals in therapy included joining with the couple and remaining objective in her assessment of the relationship. However, she found her neutral position difficult to maintain as she tended to side with Melissa, disagreeing with Mark's apparent devaluing of women. Elizabeth values gender equality and autonomy in relationships. In addition, she believes that children are harmed by marital conflict and poor parental examples of marital roles. At the same time Elizabeth felt uneasy sharing these values with the couple, as she did not want to appear moralistic or preachy. She had been taught to remain neutral in her interactions with clients, and to avoid projecting her own beliefs or biases onto them.

As therapy continued, Elizabeth felt stuck in her work with this couple. Despite her attempt to remain detached, she was aggravated with Mark's condescending attitude, which affected the way she viewed him and interacted with him. Although her goal was neutrality, Elizabeth's questions and attitudes were influenced implicitly by her values. Elizabeth's challenges to Mark were not explicit, but the attitude underlying the questions she asked and the research she referred to were experienced by Mark as accusations. Mark responded with increased defensiveness, becoming more uncooperative and deliberately making statements that provoked Elizabeth.

Elizabeth brought the case up in supervision. Her supervisor reviewed the case and felt that she was not being directive enough to overcome Mark's "resistance." The supervisor 
suggested paradoxical directives and homework assignments. Elizabeth resisted these suggestions because she valued a collaborative approach, and she felt uncomfortable about trying them.

Although simplistic in description, the case above illustrates the influence of values for all participants. The act of meeting in a therapy setting indicates a valuing of the relationship by the couple and the therapist. The clash of values regarding gender and marital roles, as well as the accompanying emotional reactions, reveal a preference for certain behaviors and attitudes over others. Elizabeth's valuing of the value-neutral ideal appears as she resists saying certain things in session, and her valuing of a collaborative approach is at odds with her supervisor's valuing of more directive approaches. Furthermore, even though conflict in marriage is often related to value differences (Gottman, 1999), Elizabeth's attempts to remain value-neutral or to avoid values in therapy may be implicitly sending to her clients a message that values avoidance is better than openly addressing value differences.

To modify this scenario, various ways of practicing in a more value-aware fashion could have been explored. Elizabeth could have been more aware of her own preferences and judgments, possibly having examined these in training or supervision activities designed to help therapists develop such awareness, as in the following hypothetical scenario:

Supervisor: It seems that you are having a struggle with this couple, especially the husband. Why do you think you are having difficulty working with this client?

Elizabeth: Well, I don't agree with his attitude about marriage and the way he treats his wife.

Supervisor: It seems that there may be some differences in the values you and your client hold regarding these issues. What are your own values regarding husband-wife relationships? In other words, what do you believe about marriage, and what kind of relationship do you think husbands and wives should have? (Elizabeth answers)

Supervisor: How about the husband, what are his values regarding these things? I suggest that you ask him to talk about his beliefs regarding marriage and husbandwife relationships. Also, let's just assume that his values are different than yours; is it necessary to have congruence between your value system and that of the client(s)? Why (or why not)?

Elizabeth also could become more attuned to values issues when they occur in session and identify when values seem to be conflicting, or where one set of values (such as her own) is being forced on another. For example, Elizabeth could initiate a therapeutic conversation about her clients' values regarding marriage and marital roles:

Elizabeth: As I have thought about our sessions, I've noticed that there are some things that we see differently, and it seems that there are times when we struggle over whose view is right. While reflecting on this, I realized that I may not have an accurate understanding of your beliefs and values regarding marriage. Help me understand your view of the role of a husband in marriage. (The husband responds.) Elizabeth: What kind of relationship do you think husbands and wives should have? (Following the husband's response, Elizabeth directs the husband and wife to turn their chairs and speak to each other.)

Elizabeth: Talk about how your views of a husband's role in marriage are similar to each other and how they are different. (Elizabeth then coaches them in a constructive conversation about their respective values regarding marriage and a husband's role). 
In addition to helping her clients recognize and respectfully converse about their own values, Elizabeth could also be more up front with her clients, appropriately sharing her values related to marital equality and conflict. Additionally, she could take time every few sessions to follow up on this discussion. She could ask for the client's perspective on how therapy was proceeding, and she could continually make overt the process that they were engaging in, and try to comment on times when she thought their respective values were playing a role in therapy.

In supervision, a joint examination of their respective values could help the supervisor and supervisee increase awareness and avoid a struggle over the difference in their approaches, as suggested in the following example:

Supervisor: It seems to me that you are reluctant to try these techniques with this couple.

Elizabeth: Well...yes. That's true.

Supervisor: Help me understand what it is that keeps you from using them?

Elizabeth: Well, I see these techniques as kind of manipulative. They have sort of a pragmatic "the ends justify the means" feel to them that just doesn't fit well with me. I believe that the means inevitably influence the ends. I prefer to be more collaborative and straightforward with clients.

Supervisor (recognizing this as an opportunity for a discussion of values): So the values you hold about the therapist's role may not fit well with the values you see in these interventions.

Elizabeth: Yes. And also with my values regarding people and the nature of client change.

Supervisor: Tell me a little bit about your beliefs about people and the nature of change.

(Elizabeth answers the supervisor's question.)

Supervisor: OK. What are some interventions that are more consistent with your values? How might they invite change with this couple?

By having such a conversation with the therapist, the supervisor not only addresses the differences in their values, but she also models a way of addressing values differences with clients. This also opens the door for similar discussions in therapy and supervision in the future.

\section{Implications for MFT Research}

The majority of the studies published in MFT journals incorporate research designs that are based on the rationalist/empiricist foundation of the scientific method (Hawley, Bailey, \& Pennick, 2000). Despite suggestions to broaden scientific inquiry by using diverse methods and being more open about author context (Knapp, 2002; Pinsof \& Wynne, 2000), the traditional, objectivist presentation of findings in academic journals predominates. This formalism is functional in many ways, but changes have been recommended that may bring research closer to the lived experience of therapists and clients, and may help bridge the gap that has historically existed between researchers and clinicians (Pinsof \& Wynne, 2000; Sprenkle \& Piercy, 2005).

There is a trend toward using a greater variety of methodological approaches in MFT scholarship (Addison et al., 2002; Sprenkle \& Piercy, 2005). This development provides an opportunity for critical reconsideration of the assumptions and values that both traditional 
and newer approaches contain. As Slife (2004) has said: "Science is investigation and examination in all its forms. A scientist has no obligation to stop with empirical investigation. If the assumptions and values that are used to understand particular phenomena become problematic, creative scientists investigate those assumptions"' (p. 45). Qualitative methods, for example, rest on a philosophical foundation that assumes researcher's values will inevitably influence the research process. Qualitative methods, therefore, tend to be more explicit than quantitative methods in requiring the researchers to be self-aware and transparent in the research and reporting process (Denzin \& Lincoln, 2000).

Whether conducting qualitative or quantitative research, investigators can do a better job of accounting for their own values, biases, and theoretical commitments, as well as those inherent in the research methods they employ. This would improve the authenticity of the work by explicating more clearly the assumptions and values informing the research (Allen, 2000; Mowery \& Walters, 2005). Knapp (1999, 2002) suggests that family scholars need to re-think the traditional form of academic reports, with their valuing of third-person, objective language. He suggests a more transparent model of reporting research that emphasizes the author's participation, epistemological framework, and voice. Furthermore, Blow and Hartnett (2005) argue that researchers who are investigating value-laden topics should disclose their values related to the topic so that readers can better understand the motivation behind the research. This is a way of identifying potential "conflicts of interest" or personal values that may influence the methodology or findings. For instance, researchers may be funded by an organization that is invested in a particular outcome, or they may be investigating a social issue that is highly charged or divisive (Duncan, Miller, \& Sparks, 2000; Green, 2003; Rosik, 2003). Formal research reports obfuscate the values of the researcher, presenting findings as though they are a report of reality, rather than a particularly situated investigation. This can lead to distorted or unhelpful results.

\section{Conclusion}

Doherty and Boss (1991) challenged family therapists to be more aware of how values play a part in their work. Furthermore, they challenged the field to continue the discussion of ethics and values and suggested that this should be part of the training and continuing education for MFT professionals. While ethics (as defined above) are addressed thoroughly in training programs as well as in the AAMFT Code of Ethics, additional effort is needed to meet the challenge from Doherty and Boss to adequately address values in our training and practice. The neglect of values discussions in MFT training programs may inadvertently give students and therapists the idea that values are not an appropriate topic for therapy and that they can be value-neutral with their clients (Doherty, 1995). Like parents who are not comfortable talking with their children about sex, avoiding the topic of values may leave trainees with the vague feeling that there is something wrong or inappropriate about such discussions.

We encourage continued dialogue about values and family therapy. This discussion may help professionals overcome their reluctance to grapple with this complex topic, and it may also help therapists assist clients to better understand their own lives and choices. The conversation about values can be continued through scholarly debate, as well as in MFT ethics classes, theory/models courses, research methods classes, and clinical practicum and supervision. Additionally, continuing education at national and regional professional conferences should include dialogue on the role of values in therapy. 
Future research could explore types of values that family therapists hold and how these tend to be articulated in clinical practice. Scholars could examine what values lead individuals to a career in MFT and how these values may relate to the use of specific therapy models or research in their clinical work. It also may be helpful to understand the congruence (or lack thereof) between therapists' values, the values inherent in the therapy approaches they use, and whether these values are helpful in facilitating client change.

Acknowledgments The authors wish to thank Gregory Brock, Ph.D. and Robyn Mowery, Ph.D., Department of Family Studies, University of Kentucky, for their helpful reviews of an earlier draft of this paper.

\section{References}

Addison, S. M., Sandberg, J. G., Corby, J., Robila, M., \& Platt, J. J. (2002). Alternative methodologies in research literature review: Links between clinical work and MFT effectiveness. American Journal of Family Therapy, 30, 339-372.

Allen, K. R. (2000). A conscious and inclusive family studies. Journal of Marriage and the Family, 62, 4-17. Aponte, J. H. (1985). The negotiation of values in therapy. Family Process, 24, 323-338.

Bergin, A. E. (1980). Psychotherapy and religious values. Journal of Consulting and Clinical Psychology, 48, 95-105.

Beutler, L. E. (1979). Values, beliefs, religion and the persuasive influence of psychotherapy. Psychotherapy: Theory Research and Practice, 16, 432-440.

Blow, A. J., \& Hartnett, K. (2005). Infidelity in committed relationships I: A methodological review. Journal of Marital and Family Therapy, 31, 183-216.

Brennan, J. F. (1995). Readings in the history and systems of psychology. Englewood Cliffs, NJ: Prentice Hall.

Brock, G. W. (1993). Ethical guidelines for the practice of family life education. Family Relations, 42, $124-127$.

Carlson, T. D., \& Erickson, M. J. (1999). Recapturing the person in the therapist: An exploration of personal values, commitments, and beliefs. Contemporary Family Therapy, 21, 57-76.

Coles, R. (1989). The call of stories: Teaching and the moral imagination. Boston: Houghton Miflon.

Corey, G., Corey, M. S., \& Callanan, P. (2003). Issues and ethics in the helping professions (6th ed.). Pacific Grove, CA: Brooks/Cole.

Crane, D. R., Wampler, K. S., Sprenkle, D. H., Sandberg, J. G., \& Hovestadt, A. J. (2002). The scientistpractitioner model in marriage and family therapy doctoral programs: Current status. Journal of Marital and Family Therapy, 28, 75-83.

Del Campo, R. L., Roney, J. R., Pais, S., \& Campbell, S. (2003). Ethics case study. Presentation given at the annual conference of the American Association of Marriage and Family Therapy, October 2003, Long Beach, CA.

Denzin, N. K., \& Lincoln, Y. S. (2000). Introduction: The discipline and practice of qualitative research. In N. Denzin, \& Y. Lincoln (Eds.), Handbook of qualitative research (2nd ed., pp. 1-28). Thousand Oaks, CA: Sage.

Doherty, W. J. (1995). Soul searching: Why psychotherapy must promote moral responsibility. New York: Basic Books.

Doherty W. J., \& Boss, P. G. (1991). Values and ethics in family therapy. In A. S. Gurman, \& D. P. Kniskern (Eds.), Handbook of family therapy (pp. 606-637). New York: Brunner/Mazel.

Duncan, B., Miller, S., \& Sparks, J. (2000, March/April). Exposing the mythmakers: How soft sell has replaced hard science. Psychotherapy Networker, 24, 52-53.

Fisher-Smith, A. M. (1999). From value neutrality to value inescapability: A qualitative inquiry into values management in psychotherapy. Unpublished doctoral dissertation. Brigham Young University.

Fowers, B. J. (2001). The limits of a technical concept of a good marriage: Exploring the role of virtue in communication skills. Journal of Marital and Family Therapy, 27, 327-340.

Gladding, S. T., Remley Jr. T. P., \& Huber, C. H. (2001). Ethical, legal, and professional issues in the practice of marriage and family therapy (3rd ed.). Upper Saddle River, NJ: Merrill Prentice Hall.

Goldner, V. (1988). Generation and gender: Normative and covert hierarchies. Family Process, $27,31-47$.

Gottman, J. M. (1999). The marriage clinic: A scientifically-based marital therapy. New York: W. W. Norton \& Company. 
Green, R. (2003). When therapists do not want their clients to be homosexual: A response to Rosik's article. Journal of Marital and Family Therapy, 29, 29-38.

Hare-Mustin, R. T. (1987). The problem of gender in family therapy theory. Family Process, 26, 15-27.

Hawley, D. R., Bailey, C. E., \& Pennick, K. A. (2000). A content analysis of research in family therapy journals. Journal of Marital and Family Therapy, 26, 9-16.

Holton, G. (1988). Thematic origins of scientific thought: Kepler to Einstein. Cambridge, MA: Harvard University Press.

Hubble, M. A., Duncan, B. L., \& Miller, S. D. (1999). The heart and soul of change: What works in therapy. Washington, D.C.: APA.

Jensen, J. P., \& Bergin, A. E. (1988). Mental health values of professional therapists: A national interdisciplinary survey. Professional Psychology: Research and Practice, 19, 290-297.

Jensen, J. P., Bergin, A. E., \& Greaves, D. W. (1990). The meaning of eclecticism: New survey and analysis of components. Professional Psychology: Research and Practice, 21, 124-130.

Knapp, S. J. (1999). Constituting 'science' in family science: Beyond positivistic circumscriptions. Family Science Review, 12, 22-33.

Knapp, S. J. (2002). Authorizing family science: An analysis of the objectifying practices in family science discourse. Journal of Marriage and Family, 64, 1038-1048.

Lageman, A. G. (1993). The moral dimensions of marriage and family therapy. Lanham, MD: University Press of America.

Melito, R. (2003). Values in the role of the family therapist: Self determination and justice. Journal of Marital and Family Therapy, 29, 3-11.

Micucci, J. A. (1998). The adolescent in family therapy: Breaking the cycle of conflict and control. New York: Guilford Press.

Mowery, R. L., \& Walters, L. H. (2005). Getting to the bottom of the spanking debate Bringing in the ethics of research. In V. L. Bengtson et al. (Eds.), Sourcebook of family theory and research (pp. 607-611). Thousand Oaks, CA: Sage.

Nagel, T. (1986). The view from nowhere. New York: Oxford University Press.

Nichols, M. P., \& Schwartz, R. C. (2006). Family therapy: Concepts and methods (7th ed.). Boston, MA: Allyn \& Bacon.

Odell, M., \& Stewart, S. P. (1993). Ethical issues associated with client values conversion and therapist value agendas in family therapy. Family Relations, 42, 128-133.

Packer, M. J., \& Addison, R. B. (1989). Entering the circle: Hermeneutic investigation in psychology. New York: SUNY Press.

Patterson, C. H. (2000). Understanding psychotherapy: Fifty years of client-centered theory and practice. Herefordshire, England: PCCS Books.

Peterson, C., \& Seligman, M. E. P. (2004). Character strengths and virtues: A handbook and classification. New York: Oxford University Press.

Pinsof, W. M., \& Wynne, L. C. (2000). Toward progress research: Closing the gap between family therapy practice and research. Journal of Marital and Family Therapy, 26, 1-8.

Polkinghorne, D. (1983). Methodology for the human sciences: Systems of inquiry. Albany, NY: SUNY Press.

Richards, P. S., \& Bergin, A. E. (1997). A spiritual strategy for counseling and psychotherapy. Washington, DC: American Psychological Association.

Rokeach, M. (1973). The nature of human values. New York: Free Press.

Rosik, C. H. (2003). When therapists do not acknowledge their moral values: Green's response as a case study. Journal of Marital and Family Therapy, 29, 39-45.

Slife, B. D. (1993). Time and psychological explanation. Albany, NY: SUNY Press.

Slife, B. D. (2004). Theoretical challenges to therapy practice and research: The constraint of naturalism. In M. Lambert (Ed.), Bergin and Garfield's handbook of psychotherapy and behavior change (5th ed., pp. 44-83). New York: Wiley.

Slife, B. D., Hope, C., \& Nebeker, R. S. (1999). Examining the relationship between religious spirituality and psychological science. Journal of Humanistic Psychology, 39(2), 51-85.

Slife, B. D., \& Williams, R. N. (1995) What's behind the research? Discovering hidden assumptions in the behavioral sciences. Thousand Oaks, CA: Sage.

Sprenkle, D. H., \& Piercy, F. P. (2005). Pluralism, diversity, and sophistication in family therapy research. In D. H. Sprenkle, \& F. P. Piercy (Eds.), Research methods in family therapy (2nd ed., pp. 3-18). New York: Guildford.

Thomas, V. (1994). Value analysis: A model of personal and profession ethics in marriage and family counseling. Counseling \& Values, 38, 193-204. 
Tjeltveit, A. C. (1986). The ethics of value conversion in psychotherapy: Appropriate and inappropriate therapist influence on client values. Clinical Psychology Review, 6, 515-537.

Vachon, D. O., \& Agresti, A. A. (1992). A training proposal to help mental health professionals clarify and manage implicit values in the counseling process. Professional Psychology: Research and Practice, $23,509-514$.

Wampler, K. S. (2002). Editorial: Research. Journal of Marital and Family Therapy, 28, 1-2.

Watson, G. (1958). Moral issues in psychotherapy. American Psychologist 13, 574-576.

White, M. (1993). Narrative therapy using a reflecting team (Video recording). Alexandria, VA: ACA.

Whiting, J. B., Nebeker, R. S., \& Fife, S. T. (2005). Moral responsiveness and discontinuity in therapy: A qualitative study. Counseling and Values, 50, 20-37. 